\title{
The effect of lake sediment on the hatching success of Daphnia ephippial eggs
}

\author{
Jacek RADZIKOWSKI, Anna SIKORA, Mirosław ŚLUSARCZYK \\ Department of Hydrobiology, Faculty of Biology, Biological and Chemical Research Centre, University of Warsaw, Żwirki i Wigury \\ 101, 02-089 Warszawa, Poland \\ *Corresponding author: jacekasdf@wp.pl
}

\begin{abstract}
A large proportion of lake-Daphnia ephippia which are shed by females in the water column sink to the bottom, where they form an assemblage of dormant stages known as an egg bank. Although the quantity of zooplankton eggs in such an assemblage may exceed tens of thousands per square meter, the annual hatch from this bank is usually extremely low (from zero to a few dozens animals per square meter per year). This low-hatching phenomenon may be caused by isolation from hatching stimuli by water or sediment layers, a mechanical barrier formed by sediment that does not allow hatchlings to reach the water, or by a bet-hedging strategy of the resting eggs. The aim of our study was to determine the extent to which coverage by lake sediment may affect the hatching of Daphnia dormant eggs. The ephippia of lake-Daphnia (longispina species complex), covered by sterilized lake sediment of different thicknesses (0, 0.25 , $0.5,1,2$ and $4 \mathrm{~cm} ; 4$ replicates per treatment), were incubated for 8 weeks in lab controlled conditions. The results indicate that even the thinnest tested layer $(0.25 \mathrm{~cm})$ may completely inhibit hatching of ephippial eggs. A few Daphnia neonates were observed in two (of five) sediment treatments, while dozens of animals hatched in the control one. In the second experiment we determined that the sediment sterilization process did not affect the hatching proportion of ephippial eggs (when compared to the treatment with unsterilized sediment). We hypothesize that the observed inhibition of Daphnia hatching in the main experiment, which may cause a serious problem for Cladoceran populations in lakes where no sediment mixing occurs, may be caused by low light intensity, anoxic conditions or a physical barrier created by the sediment.
\end{abstract}

Key words: Daphnia; egg bank; ephippia; sediment; dormancy, hatching stimuli.

Received: September 2015. Accepted: June 2016.

\section{INTRODUCTION}

Many aquatic invertebrates, including cladocerans of the genus Daphnia, survive seasonal periods of adverse environmental conditions in the form of dormant eggs (Caceres, 1997; Ślusarczyk, 1999; Gyllström and Hansson, 2004). When facing environmental deterioration Daphnia females form an ephippium composed of up to two diapausing eggs enclosed in a chitinous envelope derived from their carapace (Schultz, 1977), which they shed either at the water surface or in the water column (Pietrzak and Ślusarczyk, 2006). Ephippia shed in the water column usually sink to the bottom, where they may form an egg bank (De Stasio, 1989) - an assemblage of dormant stages which can remain viable in the sediment for years. Ephippial eggs of Daphnia are known to be extremely long-lived, as they can survive in lake sediments for years, decades or even centuries (Caceres, 1998; Frisch et al., 2014; reviewed by Radzikowski, 2013). Although the density of viable resting eggs of planktonic crustaceans can exceed tens of thousands per square meter (Herzig, 1985; Carvalho and Wolf, 1989; Brendonck and De Meester, 2003; Caceres and Tessier, 2004) only a small portion of this pool hatch annually (Wolf and Carvalho, 1989; Caceres, 1998; Rother et al., 2010). This suggests that most of the resting forms may be trapped in the sediment. In the top layer of sediment the aforementioned low-hatching phenomenon might be explained as an element of a bet-hedging strategy (Cohen, 1966; Brendonck and De Meester, 2003; Evans and Dennehy, 2005) - e.g., only part of the eggs hatch during the first favourable occasion, to reduce the risk of extermination of the entire population by unpredictable catastrophic events. The remaining eggs may hatch at subsequent favourable seasons. Just slightly deeper, a few-millimetres-thick layer of sediment may isolate the resting forms from environmental cues required for their activation (i.e., temperature and light/photoperiod; Stross, 1966; Davison, 1969; Schwartz and Hebert, 1987; Vandekerkhove et al., 2005). Furthermore, the concentration of oxygen in the deeper sediment layers may be reduced both in marine (Revsbech et al., 1980) and freshwater habitats (Sweerts and De Beer, 1989; Müller et al., 1998; Holmer and Storkholm, 2001), what may also inhibit the hatching of dormant eggs (Kasahara et al., 1975; Uye et al., 1979; Lutz et al., 1992). Moreover, sediment layers may act as a physical barrier preventing exephippial neonates from entering the water column (Gleason et al., 2003). The question arises: how thick does the sediment layer have to be to inhibit the hatching of Daphnia ephippial eggs? Caceres and Hair- 
ston (1998) speculated that the active fraction of an egg bank (defined as the depth to which eggs can receive the hatching cue and hatch) is limited to the top 1 centimeter of sediment. They suggested that resting forms buried slightly (a few centimeters) deeper are unable to enrich the active population unless sediment mixing occurs. The mixing events are, of course, observed in most lakes and can be caused by abiotic (e.g., storms; Kerfoot et al., 2004; gas bubbles forming in the sediment; Meier et al., 2011 ) or biotic (invertebrates and fish burying in the sediment; Gyllström and Hansson, 2004) factors.

But what happens with buried ephippia in sites where no mixing occurs? Some hints can be found in the research on copepods. Hairston and Kearns (2002) estimated that effective hatching cues may only penetrate the top 1.5-3.3 mm of sediment. Uye (1980) did not observe hatching of dormant eggs of marine calanoid copepods of the genus Acartia covered by $5-7 \mathrm{~mm}$ of sediment. Ban and Minoda (1992) did not observe the hatching of eggs of freshwater calanoid Eurytemora affinis that were sandwiched between two (1.5-2 mm thick) layers of sediment. In both the above studies the lack of oxygen was suggested as the factor that inhibited copepod hatching. For cladocerans, the effect of sediment thickness on the hatching of dormant eggs, according to our knowledge, was determined only once, by Gleason and co-workers (2003). The researchers tested the effect of sieved upland soil (with particle size typical for erosional sediment) on wetland egg banks. A $5 \mathrm{~mm}$ thick sediment layer reduced hatching of various invertebrates (including cladocerans) by $99.7 \%$, compared to a control with no sediment coverage. The thicker sediment layers $(10$ and $20 \mathrm{~mm})$ further reduced invertebrate emergence. While those results show the negative effect of sediment coverage on cladoceran hatching, they are probably not representative for most lakes, as the cladoceran fauna of shallow wetland reservoirs differs significantly from animals inhabiting deep lakes (Hann, 1995). The physical and chemical structure of lake sediments probably also differs from the soil sediment used in this study. Thus, the aim of our study was to determine the threshold thickness of lake sediment which inhibits the hatching of Daphnia ephippial eggs.

\section{METHODS}

\section{Sampling and isolation of the ephippia}

All the sampled ephippia were isolated from sediment collected in Lake Roś, North-East Poland. Roś is a large (1887.7 ha) and deep (max. depth 31.8 m; Jańczak, 1999) eutrophic flow-through lake. The production of ephippia is observed mainly in autumn (October and November; Grabowski, 2006) and the dominant cladoceran species in this lake is Daphnia cucullata (Surga, 2007). The highest D. cucullata densities were noted in September and Octo- ber. The lake zooplankton was rarely sampled in winter. In the last years ice cover occurred on Lake Roś almost every winter. Cladocerans were either absent or present in extremely low densities in the water column under the ice. In season 2005-2006 Daphnia appeared in the water column in May and disappeared in February of the following year (Surga, 2007). Oxygen levels lower than $1 \mathrm{mg} \mathrm{O}_{2} \mathrm{~L}^{-1}$ are often observed deeper than 15 meters in summer and early autumn. In 2005 oxygen depletion was observed since July till October (own unpublished data). Lake Roś is dimictic. In the deepest parts of the lake, water temperature reaches $6-8^{\circ} \mathrm{C}$ in the late spring (the most likely Daphnia hatching period; Surga, 2007). The sediment was collected from the deepest part of the lake $\left(\sim 30 \mathrm{~m}\right.$; $\sim 53^{\circ} 40^{\prime} 11^{\prime \prime} \mathrm{N}$, $\left.21^{\circ} 55^{\prime} 33^{\prime \prime} \mathrm{E}\right)$ in June 2013, during the daytime, using an Ekman sampler modified to collect the top 2-3 cm of sediment only. While no data on sedimentation rates in Lake Roś is available, our personal observations indicate that it may exceed $1 \mathrm{~cm}$ per year. Hence, the ephippia sampled were probably not older than 2-3 years and, as the sampling was performed during the autumnal peak of ephippia production, a large proportion of the sampled resting forms was probably only a few weeks old. Collected samples were immediately transferred to black plastic bags and placed in a portable refrigerator $\left(4^{\circ} \mathrm{C}\right)$, to minimize the risk of thermal activation of the ephippial eggs. Subsequently the samples were transported to a laboratory in Warsaw for storage (a dark cold room, $4-5^{\circ} \mathrm{C}$, for $\sim 2$ months). After the storage period, the sediment was removed from the cold room and rinsed through a $150 \mu \mathrm{m}$ sieve with cold tap water (cold water was used to minimize the risk of thermal activation of the eggs). Subsequently, the sieved sediment was flooded with cooled $\left(4^{\circ} \mathrm{C}\right)$ 1:1 sucrose:filtered tap water solution and centrifuged for $10 \mathrm{~min}$ at $1500 \mathrm{rpm}$ (365 g; modified sugar flotation method; Onbé, 1978). The supernatant was rinsed with cold tap water through a $150 \mu \mathrm{m}$ sieve and the isolated material was placed, using a glass pipette, in cooled $\left(4^{\circ} \mathrm{C}\right)$, filtered $(1 \mu \mathrm{m})$ lake water in darkness, for the time of ephippia isolation prior to the experiment (a few hours). The experiment started the same day the ephippia were isolated.

\section{The experimental setup}

The isolated ephippia were further selected under a stereoscopic microscope equipped with cold LED light. Therefore, all ephippial eggs could have been exposed to light stimuli for short time periods (during sediment sampling and sieving and ephippia isolation) prior to the experiment. We are not aware of any data regarding the length of a single exposition to light needed to activate Daphnia dormant eggs, but results for anostracan Branchipodopsis wolfi (Pinceel et al., 2013) show that short expositions ( $<2$ h) can activate only a small percentage of resting eggs. If this is also the case in Daphnia, the short exposition to light 
during the preparation of our experiment should have a negligible effect on the hatching of Daphnia in the present study. For the experiment only ephippia of Daphnia longispina species complex containing apparently viable eggs were selected. The vast majority of the ephippia used in the experiment contained two apparently viable eggs. Most of the ephippia were transparent, which allowed us to estimate the quantity and quality of the eggs in each ephippium. A small proportion of dark coloured opaque ephippia were also used (opening of similar ones revealed that most of them also contained two eggs). Samples of 50 randomly chosen ephippia were placed on the bottom of $250 \mathrm{~mL}$ glass beakers filled with $100 \mathrm{~mL}$ of cooled $\left(4^{\circ} \mathrm{C}\right)$, filtered $(0.45 \mu \mathrm{m})$ lake water in 4 replicates per treatment. The bottom and walls of each beaker were covered with black paint to allow illumination only from the top. The ephippia in the beakers were covered with sterilized (boiled with deionized water for $30 \mathrm{~min}$ and then cooled to $4^{\circ} \mathrm{C}$ ) sediment collected from Lake Roś during the same sampling session. The sediment was applied, using a glass pipette, in layers of different thickness: 0.25, 0.5, 1, 2 and $4 \mathrm{~cm}$. Four beakers containing ephippia not covered with sediment were treated as a positive control, while four beakers with $2 \mathrm{~cm}$ of sterilized sediment (with no ephippia added) were treated as a negative control.

Shortly after the application of ephippia and sediment, the beakers were placed in a water bath for incubation. In order to obtain the highest hatching rates, we used $8 \pm 0.1^{\circ} \mathrm{C}$ for ephippia incubation, as our preliminary tests indicated that incubation temperature between 6 and $9^{\circ} \mathrm{C}$ provide the highest hatching rates from ephippia originating from the Lake Roś and similar Polish lowland lakes (Krupińska, 2014; own unpublished data). The water bath was illuminated with fluorescent light at an intensity of $20 \mu \mathrm{mol} \mathrm{m}$ ${ }^{2} \mathrm{~s}^{-1}$, measured above the sediment, which is a standard light intensity used in our laboratory to hatch/breed Daphnia. A 16:8 L:D light regime was used. This photoperiod was successfully used by Vandekerkhove and co-workers (2005) to hatch various species of Cladocera from similar climate and indicated as more effective than the constant light conditions. The temperature and photoperiod that we used in the experiments were similar to ones observed in spring (Daphnia hatching time) in the Lake Roś.

Every two days all the newly hatched Daphnia were removed from the beakers, using a fine glass pipette, and counted. The experiment continued for 53 days, until hatching almost ceased (a total number of 3 animals hatched during the last 14 days of incubation).

\section{The effect of sediment sterilization on Daphnia hatching}

To determine if the sediment sterilization process might have affected the hatching of ephippial eggs (i.e., if any chemical substances harmful to Daphnia were pro- duced during sediment boiling what could have resulted in lowered hatching in the sediment treatments of the main experiment) a second experiment was conducted. The process of ephippia isolation and sediment sterilization was the same as described above. Portions of 50 ephippia in 4 replicates were placed in transparent plastic tubes ( $30 \mathrm{~mm}$ wide, $40 \mathrm{~mm}$ long) ended by a $150 \mu \mathrm{m}$ nylon mesh. Tubes with ephippia were positioned a few (2-4) millimetres above the $2 \mathrm{~cm}$ thick layer of sterilized or non-sterilized sediment lying at the bottom of darkened $250 \mathrm{ml}$ glass beakers filled with $100 \mathrm{ml}$ of filtered $(0.45$ $\mu \mathrm{m})$, cooled lake water. The upper part of the plastic tubes protruded above the water level. Beakers with ephippia without sediment were used as a positive control while beakers with $2 \mathrm{~cm}$ of sterilized sediment were treated as a negative control. All the experimental beakers were kept in a water bath $\left(8 \pm 0.1^{\circ} \mathrm{C}\right)$ and illuminated as in the first experiment. Every two days all neonates were counted and removed from the beakers. The experiment ended after 44 days of incubation, when hatching ceased (no neonates observed for four days).

We used this different experimental setup, with ephippia placed above the sediment, for two reasons. First, we wanted to distinguish potential inhibitory effect of chemicals that might had appeared during sterilization of the sediment from the mechanical effects of the sediment coverage and lack of light or oxygen. Second, if we covered ephippia with the non-sterilized sediment in the main experiment, we would not be able to distinguish animals hatched from the experimental ephippia from hatchlings originating from viable ephippia present in the sediment (sieving the sediment prior to the experiment would, on the other hand, result in a drastic change of its structure). The experimental setup of the second experiment allowed to assess, if the mere presence of sediment (sterilized or non-sterilized) can affect hatching of the ephippial eggs.

\section{Oxygen concentration}

Due to technical issues (lack of suitable equipment) the oxygen concentration in the sediment could not be measured during the course of the two experiments. However, the oxygen content of the sediment was measured using a Unisense Oxygen Microoptode OP-430 a few months later in conditions resembling the first experimental setup. For each beaker tested, sterilized sediment, collected from lake Roś, was deposited on its bottom. Sediment of 5 different thicknesses was tested $(0.25,0.5$, 1, 2, $4 \mathrm{~cm}$; one beaker per treatment). Moreover, beakers without sediment and with $2 \mathrm{~cm}$ of unsterilized sediment were also tested. Ephippia were not added to the beakers. The treatments were not replicated, due to an insufficient quantity of Lake Roś sediment collected on the same sampling date as that used in the main experiment. The oxygen concentration was measured in the deep end of the 
sediment layers $(\sim 1 \mathrm{~mm}$ above the glass bottom of the beakers) 6 times: 2 and 24 hours after setting up the test, and then 1,2, 4 and 5 weeks later. Moreover, the oxygen concentration was measured in the water $2-3 \mathrm{~mm}$ above the sediment layers in each treatment, every time.

\section{Data analysis}

All the hatching results from both experiments are shown as a proportion of hatched individuals out of the initial number of potentially viable eggs (with the assumption that $100 \%$ is equal to 100 hatched individuals). This approach probably underestimated the hatching rates, as it is likely that not all the eggs of the experimental ephippia were actually alive at the beginning of the experiments. Nevertheless, the proportion of non-viable eggs probably did not differ between experimental beakers, since the ephippia were assigned randomly to each of them. Proportions of hatched individuals were compared using the analysis of deviance and Generalized Linear Models (GLZ) with defined log-log function and binomial error distribution in Statsoft Statistica package, version 12.5.

In the first experiment the effect of various sediment thicknesses on the quantity of hatching neonates was tested. In the second experiment the effect of different sediment treatments on the quantity of hatching individuals was investigated. Homogenous groups of treatments were determined by stepwise reduction of maximal models to their minimal adequate form according to a procedure offered by the statistical package.

\section{RESULTS}

\section{The effect of sediment thickness on the hatching of ephippial eggs}

During the course of the first experiment, Daphnia neonates were observed in the positive control and in two of the five sediment treatments (Fig. 1). In total, 104 animals were caught and identified as Daphnia (no other invertebrate genera were observed). The highest number of neonates was noted in the positive control (with no sediment; $25 \pm 6.1 \%$, mean $\pm 1 \mathrm{SD}$; Fig. 1). A few newborns were observed in the $0.5 \mathrm{~cm}$ and $4 \mathrm{~cm}$ treatments, while none were found in the remaining three sediment treatments. The mean hatching percentage in the positive control treatment differed significantly from those in the sediment treatments (GLZ, $\chi^{2}=217.2, \mathrm{P}<0.001$ ). No animals hatched in the negative control treatment, indicating that the sediment sterilization procedure was successful.

\section{The effect of sediment sterilization on Daphnia hatching}

A total number of 162 Daphnia individuals hatched in this experiment (Fig. 2). More animals hatched in the pos- itive control treatment (with no sediment - $21.5 \pm 12.5 \%$, mean $\pm 1 \mathrm{SD}$ ) than in the sterilized or not sterilized sediment treatments $(9.8 \pm 5.3 \%$ and $9.3 \pm 4.0 \%$ respectively; GLZ, $\left.\chi^{2}=30.2, \mathrm{P}<0.001\right)$ with ephippia enclosed in the

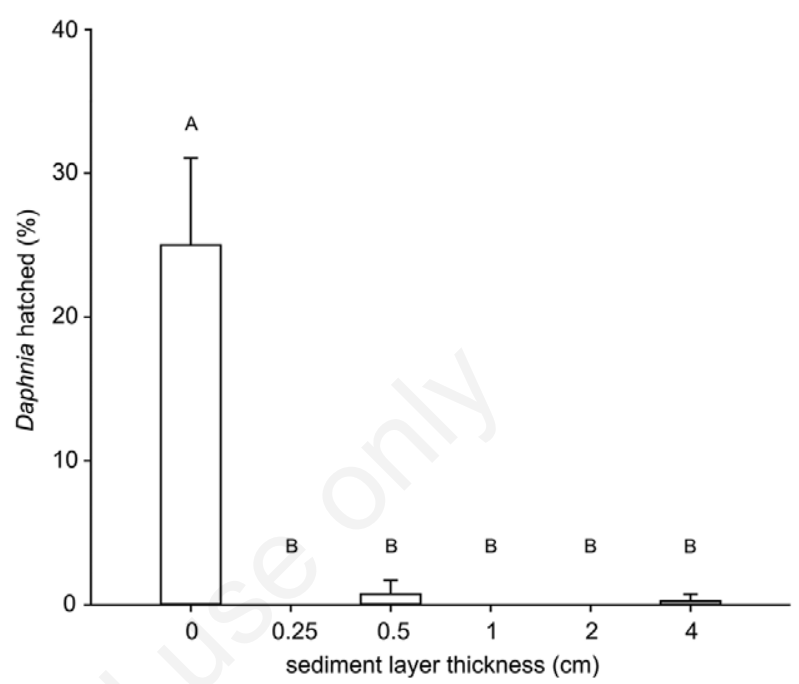

Fig. 1. Mean (+1 SD) percentage of Daphnia neonates hatched from ephippia covered by sediment of various thicknesses (duration of experiment: 53 days). Capital letters above the bars indicate homogeneous groups of treatments (GLZ with defined $\log -\log$ function and binomial error distribution; homogenous groups determined by stepwise reduction of maximal models to their minimal adequate form).

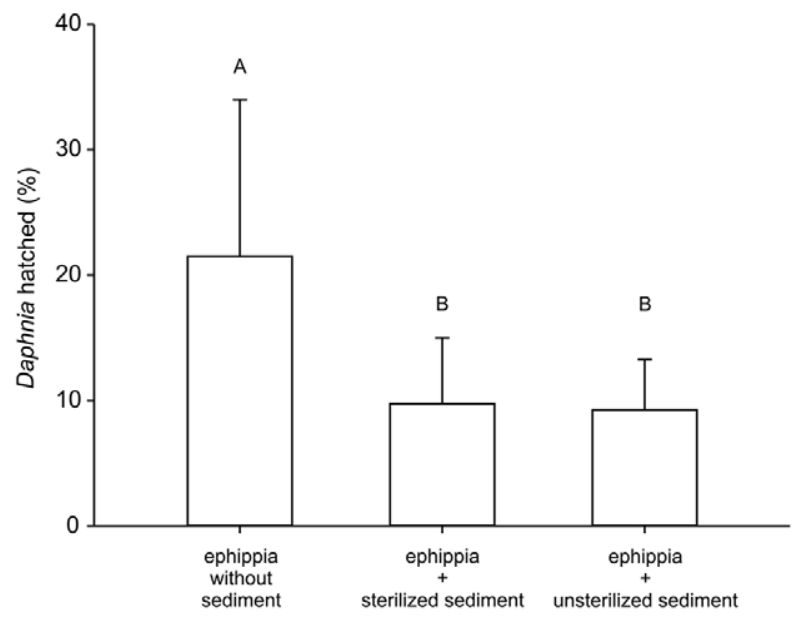

Fig. 2. Mean (+1 SD) percentage of Daphnia neonates hatched from ephippia placed above sterilized or unsterilized sediment (duration of experiment: 44 days). Capital letters above the bars indicate homogeneous groups of treatments (GLZ with defined $\log$-log function and binomial error distribution; homogenous groups determined by stepwise reduction of maximal models to their minimal adequate form). 
tubes kept a few mm above the sediment. The mean hatching percentage did not differ between the sterilized and not sterilized sediment treatments (GLZ, $\chi^{2}=0.06$, $\mathrm{P}=0.81$ ). No animals hatched in the negative control containing sterilized sediment without the tested ephippia.

\section{Oxygen concentration}

The oxygen concentration in the sediment was close to zero at all times and in all the sediment treatments (Tab. 1 ), except the $0.25 \mathrm{~cm}$ treatment on the first day of the experiment $\left(0.897 \mathrm{mg} \mathrm{O}_{2} \mathrm{~L}^{-1}=28.7 \mu \mathrm{mol} \mathrm{O}_{2} \mathrm{~L}^{-1}\right)$. The oxygen content at the bottom of the control beaker (with 100 $\mathrm{mL}$ of filtered lake water and no sediment) was high and relatively stable during the course of the experiment (11.484-11.906 $\mathrm{mg} \mathrm{O}_{2} \mathrm{~L}^{-1}=367.5-381 \mu \mathrm{mol} \mathrm{O}_{2} \mathrm{~L}^{-1}$, what is close to full saturation at $8^{\circ} \mathrm{C}$ ). The oxygen concentration measured slightly over $(2-3 \mathrm{~mm})$ the sediment surface was more variable in time and between treatments (Tab. 2), and seemed to be lower in the boiled $v s$. non-boiled $2 \mathrm{~cm}$ sediment treatment.

\section{DISCUSSION}

The maximum Daphnia hatching rates were reported in the treatments without sediment in both experiments (with means of 21.5 and $25 \%$ in the first and the second experiment respectively). A relatively large proportion of unhatched eggs in the controls may have resulted from suboptimal hatching conditions, on one hand, or a bethedging hatching mechanism (Evans and Dennehy, 2005), on the other. Such a mechanism does not allow all diapausing eggs to activate at the first favourable occasion, which secures the population from extinction by unexpected catastrophic events.

The results of the first experiment indicate that even a very thin sediment layer $(\geq 2.5 \mathrm{~mm})$ covering the ephippia may totally inhibit the hatching of dormant eggs (Fig. 1). The few neonates which appeared in the beakers containing lake sediment probably hatched from ephippia which were accidentally dragged towards the sediment surface during the setting of the experiment. Similar results, showing complete hatching inhibition by a thin layer of sediment, were previously reported for dormant eggs of calanoid copepods. A sediment layer 5-7 mm thick prevented the emergence of marine copepods of the genus Acartia (Uye, 1980), while a thinner layer (1.5-2 mm) blocked the hatching of dormant eggs of freshwater $\mathrm{Eu}$ rytemora affinis (Ban and Minoda, 1992). The inhibition of hatching by sediment coverage was also observed for other calanoid dormant forms, but the effective sediment layer thickness was not specified (Kasahara et al., 1975; Uye et al., 1979). Our work supports the results of the only study concerning hatching inhibition of cladoceran diapausing eggs by sediments that we are aware of (Glea-

Tab. 1. Dissolved oxygen concentration measured $\sim 1 \mathrm{~mm}$ above the glass bottom of the beakers in sediment layers of different thicknesses $\left(\mathrm{mg} \mathrm{O}_{2} \mathrm{~L}^{-1}\right)$.

\begin{tabular}{|c|c|c|c|c|c|c|}
\hline & & & Time cou & periment & & \\
\hline Sediment layer $(\mathrm{cm})$ & 2 hours & 24 hours & 1 week & 2 weeks & 4 weeks & 5 weeks \\
\hline 0 & 11.750 & 11.484 & 11.750 & 11,766 & 11,703 & 11,906 \\
\hline 0.25 & 0.897 & 0.069 & $<0.015$ & $<0.015$ & $<0.015$ & $<0.015$ \\
\hline 0.5 & $<0.015$ & $<0.015$ & $<0.015$ & $<0.015$ & $<0.015$ & $<0.015$ \\
\hline 1 & 0.020 & $<0.015$ & $<0.015$ & $<0.015$ & $<0.015$ & $<0.015$ \\
\hline 2 & $<0.015$ & $<0.015$ & $<0.015$ & $<0.015$ & $<0.015$ & $<0.015$ \\
\hline 4 & $<0.015$ & $<0.015$ & $<0.015$ & $<0.015$ & $<0.015$ & $<0.015$ \\
\hline 2 (non-boiled) & $<0.015$ & $<0.015$ & $<0.015$ & $<0.015$ & $<0.015$ & $<0.015$ \\
\hline
\end{tabular}

Tab. 2. Dissolved oxygen concentration measured $2-3 \mathrm{~mm}$ over the sediment layers of different thicknesses $\left(\mathrm{mg} \mathrm{O}_{2} \mathrm{~L}^{-1}\right)$.

\begin{tabular}{lcccccc} 
& \multicolumn{5}{c}{ Time course of the experiment } \\
Sediment layer $(\mathrm{cm})$ & 2 hours & 24 hours & 1 week & 2 weeks & 4 weeks & 5 weeks \\
0.25 & 5.469 & 1.688 & 1.563 & 1.719 & 2.984 & 3.719 \\
\hline 0.5 & 4.859 & 1.563 & 0.563 & 1.594 & 3.031 & 3.219 \\
1 & 5.844 & 1.375 & 0.938 & 1.781 & 2.469 & 2.813 \\
\hline 2 & 4.984 & 1.469 & 0.516 & 0.313 & 2.563 & 2.344 \\
4 & 4.375 & 1.406 & $*$ & 1.406 & 3.313 & 3.531 \\
\hline 2 (non-boiled) & $*$ & 1.969 & 1.875 & 031 \\
\hline
\end{tabular}

*Missing values. 
son et al., 2003). As the type of sediment and species composition differ in our study from those tested in the aforementioned studies, our findings can be treated as novel ones, more representative for Daphnia inhabiting deep lowland lakes.

The observed reduction of hatching in ephippia covered by lake sediment (Fig. 1) might have been caused by several reasons. First of all, even a thin layer of dark sediment is likely to cut-off ephippia from the light. Light (or changes in photoperiod) is considered to be one of the most important hatching stimuli for Daphnia dormant eggs (Pancella and Stross, 1963; Davison, 1969; PérezMartínez et al., 2013). On the other hand, lack of light is known as a factor inhibiting hatching of Daphnia ephippial eggs. For instance, Pancella and Stross (1963) successfully hatched Daphnia pulex from $40-50 \%$ ephippial eggs when they were incubated with light, while only marginal hatching was observed when eggs were incubated in darkness. Similar inhibition of hatching in darkness was observed in laboratory population of $D$. pulex by Stross (1966) and in lake-Daphnia by Carvalho and Wolf (1989). Also recent studies on tropical D. ambigua and D. laevis have shown that the absence of light negatively affected hatching of Daphnia dormant eggs (Paes et al., 2016). The existing body of evidence indicates however, that marginal hatching of Daphnia diapausing eggs may occur even without light activation. Stross (1966) reported hatching of $D$. pulex ephippial eggs without light after a few months of storage in darkness. The author hypothesized that long storage in constant darkness might have eliminated the prerequisite for light activation. Hatching in the dark was also observed in a long-term experiment on ephippial eggs of $D$. pulicaria by Caceres and Schwalbach (2001), by Radzikowski (ephippial eggs of various Daphnia species; personal observation) in sediment stored in a dark cold room for several weeks and also recently by Paes and co-workers (2016). Furthermore, the hatching of resting eggs in the dark was observed in a few species of marine (Uye and Fleminger, 1976; Uye et al., 1979) and a single species of freshwater (Eurytemora affinis; Ban and Minoda, 1992) calanoid copepods. Nevertheless, Daphnia hatching in darkness is not a common phenomenon, thus we hypothesize that the lack of light might have been one of the crucial factors inhibiting Daphnia emergence in our study.

Another important hatching stimulus for zooplankton dormant eggs is temperature (Stross, 1966; Kasahara et al., 1975; Vandekerkhove et al., 2005). In our experiment, the temperature was kept constant in all treatments (including the positive no sediment control, where quite intense hatching occurred) so this factor was definitely not the one responsible for hatching inhibition in the sediment treatments. Some authors claim that oxygen availability may be another important prerequisite for the activation of zooplankton dormant forms. It was shown that at low oxygen levels the hatching of calanoid copepod dormant eggs was inhibited (Kasahara et al., 1975; Uye, 1980; Lutz et al., 1992). Similar effects of anoxia were observed also in Artemia (Clegg, 1997). We are not aware of any reports showing the inhibitory effect of anoxia on the hatching of cladoceran dormant eggs, but we expect there to be one, as it was proven that incubation in water with higher oxygen concentrations results in higher hatching rates from Daphnia magna (De Meester, 1993) and Bythotrephes longimanus (Brown, 2008) dormant eggs than incubation in water of low oxygen content. Moreover, Carvalho and Wolf (1989) suggested that anoxic conditions can prolong diapause in Daphnia. Longer development time in hypoxic conditions was later observed in dormant eggs of $B$. longimanus, compared to normoxic conditions (Brown, 2008). While we were unable to measure the oxygen content in the sediment during the hatching test, we measured it a few months later in similar conditions. The results show that shortly after the application of lake sediment to the experimental beakers, there was low or no oxygen content a few millimetres below the sediment surface (Tab. 1). These results support field observations from many eutrophic lakes (Sweerts and De Beer, 1989; Holmer and Storkholm, 2001; Maerki et al., 2009). The oxygen content of the sediment in our study was lower than the threshold level for survival of adult Daphnia individuals - $1 \mathrm{mg} \mathrm{O}_{2} \mathrm{~L}^{-1}\left(32 \mu \mathrm{mol} \mathrm{O}_{2} \mathrm{~L}^{-1}\right)$ - suggested by Delbare and Dhert (1996). Thus it seems that low oxygen content might have been another factor responsible for low hatching levels of Daphnia in the sediment treatments in the present study. This suggests that eggs that do not hatch quickly after sinking to the bottom may be buried by dark anoxic sediment, which inhibits their further development. Obviously, the sedimentation rates vary between lakes. In deep areas of oligotrophic lakes the sedimentation rate may not exceed $1 \mathrm{~mm}$ per year (Kotarba et al., 2002) and high oxygen levels can occur in the whole water column (Holmer and Storkholm, 2001), so there is a relatively small chance for ephippia to be buried quickly by thick, anoxic sediment layers. On the other hand, in eutrophic lakes, where waters are often anoxic near the bottom and the sedimentation rates are high (up to a few cm per year; Gąsiorowski and Hercman, 2005), Daphnia dormant forms can be quickly buried by anoxic sediment, which might inhibit their hatching. Unfortunately, in our experimental setup we were unable to distinguish the effect of low light intensity from the effect of anoxia on the hatching of Daphnia. What is important, both low light intensity and low oxygen content are often observed simultaneously in the deep parts of the lowland lakes.

In the present study some non-natural substances 
(which may have appeared due to the boiling of the sediment prior the experiment) could potentially have had an effect on the hatching of Daphnia ephippial eggs. This was verified in the second experiment where ephippial eggs were incubated a few millimetres above the sterilized or unsterilized sediment. The mere presence of sediment, regardless if it was sterilized or not, reduced the hatching of ephippial eggs by $50 \%$ compared to the control (ephippia without sediment; Fig. 2). We are not sure what caused this effect: whether it were some chemical compounds originating from the sediment, or the low oxygen concentration that was observed slightly over the sediment layers (Tab. 2). We believe, however, that the suppressing effect of the sediment on the hatching of ephippial eggs placed above them in the second experiment was most likely caused by the sediment oxygen consumption (indicated in Tab. 2). Unfortunately, the precise reading of the oxygen content of the water overlaying the sediment was difficult for several reasons: i) the steep vertical gradient of oxygen concentration in overlying water and technical problems with measuring it at a similar distance from the sediment surface on each occasion; ii) the irregular sediment surface; iii) occasional unwanted stirring of the sediment during the measurements. All these factors could have potentially biased the results.

Another inhibitory effect of the sediment on hatching ephippial eggs might be related to a physical barrier for exephippial offspring imposed by the sediment layers (Gleason et al., 2003). Animals might have hatched in the sediment, but - being unable to reach the open water - died in the sediment due to oxygen depletion or starvation. However, we were unable to verify this possibility. Certainly, the assessment of the state of ephippia/eggs after the experiment could be helpful to verify the aforementioned thesis, but our experimental setup did not allow for this. The boiled lake sediment used to cover the experimental ephippia was not sieved (we aimed to keep the particles of all sizes), so it contained various particles, including cladoceran carapaces and ephippia. Moreover, some boiled ephippial eggs of Daphnia may maintain the shape of viable ones, while changing the colour to yellow/pale brown (personal observation), thus they can be misclassified as naturally dead. Therefore, the scoring of experimental eggs, ephippia or dead neonates was physically impossible after our first experiment. We could have tackled this challenge by using artificial (e.g., fine-grained silica) or sieved sediment, but this would not mimic natural conditions.

Regardless of the possible reasons (low light intensity/anoxia/physical barrier), our results indicate that even a very thin layer of lake sediment $(0.25 \mathrm{~cm})$ might act as a trap for resting forms of Daphnia (and likewise for many other planktonic animals). It seems thus that most dormant forms which do not hatch at an early occasion may be buried in the sediment trap for an indefinite amount of time, unless some external force mixes the sediment and brings them back to the surface. Stirring of the sediment may facilitate Daphnia hatching not only due to their reappearance at the sediment surface but also due to the oxygenation of their surroundings (Caceres and Schwalbach, 2001).

Certainly, in most lakes some kind of sediment mixing occurs, and there are a few factors which may cause this to happen. In shallow/nearshore waters sediment can be mixed by waves or water circulation (Marcus, 1984, 1996; Kerfoot et al., 2004). Aquatic animals inhabiting the sediment (e.g., Chironomidae, Tubificidae), hiding from visual predators (e.g., Chaoboridae) or feeding on benthic organisms (e.g., fish) can also mix sediment (Kearns et al., 1996; Hairston and Kearns, 2002; Brendonck and De Meester, 2003; Gyllström and Hansson, 2004; Ritvo et al., 2004). The intensification of human activity within lakes may further enhance the mixing of the sediment (e.g., trawling nets used in fishery, anchors, divers activity). The formation of gas bubbles within the sediment (Meier et al., 2011) might act as another (underestimated) mixing factor.

\section{CONCLUSIONS}

The fact that a huge proportion of resting stages may remain trapped in the sediment indicates that in some lakes most ephippia produced can be treated as doomed. In the light of our results, the extreme longevity of zooplankton dormant forms (Radzikowski, 2013; Frisch et al., 2014) might be seen as an adaptation to long burial with rare opportunities for hatching (when they occasionally reappear at the sediment surface in the appropriate season).

To summarize, our results are comparable with the outcome of former studies regarding the hatching of dormant eggs of calanoid copepods (Kasahara et al., 1975; Uye et al., 1979; Uye, 1980; Ban and Minoda, 1992) or other planktonic animals (Gleason et al., 2003) covered by sediment. It seems that, if no mixing occurs, even a few millimetres of sediment may completely inhibit the hatching of Daphnia diapausing eggs. Our test was done on material originating from a single lowland lake, and on animals of a single genus, thus we cannot generalize the results. We believe, however, that they may be representative of many cladoceran species and many types of lakes.

\section{ACKNOWLEDGEMENTS}

We thank Tomasz Karasek for his help during sediment sampling and Julia Dorosz and Kazimierz Więski for linguistic corrections. We also thank the anonymous reviewers for their comments which helped to improve our article. This study was supported by the Polish National Science Centre (grant 2012/05/B/NZ8/01232). 


\section{REFERENCES}

Ban S, Minoda T, 1992. Hatching of diapause eggs of Eurytemora affinis (Copepoda: Calanoida) collected from lake-bottom sediments. J. Crustac. Biol. 12:51-56.

Brendonck L, De Meester L, 2003. Egg banks in freshwater zooplankton: evolutionary and ecological archives in the sediment. Hydrobiologia 491:65-84.

Brown ME, 2008. Nature and nurture in dormancy: dissolved oxygen, $\mathrm{pH}$, and maternal investment impact Bythotrephes longimanus resting egg emergence and neonate condition. Can. J. Fish. Aquat. Sci. 65:1692-1704.

Caceres CE, 1997. Dormancy in invertebrates. Invertebr. Biol. 116:371-383.

Caceres CE, 1998. Interspecific variation in the abundance, production, and emergence of Daphnia diapausing eggs. Ecology 79:1699-1710.

Caceres CE, Hairston NG, 1998. Benthic-pelagic coupling in planktonic crustaceans: the role of the benthos. Arch. Hydrobiol. Spec. Issues Advanc. Limnol. 52:163-174.

Caceres CE, Schwalbach MS, 2001. How well do laboratory experiments explain field patterns of zooplankton emergence? Freshwater. Biol. 46:1179-1189.

Caceres CE, Tessier AJ, 2004. To sink or swim: Variable diapause strategies among Daphnia species. Limnol. Oceanogr. 49:1333-1340.

Carvalho GR, Wolf HG, 1989. Resting eggs of lake-Daphnia. I. Distribution, abundance and hatching of eggs collected from various depths in lake sediments. Freshwater Biol. 22:459-470.

Clegg JS, 1997. Embryos of Artemia franciscana survive four years of continuous anoxia: the case for complete metabolic rate depression. J. Exp. Biol. 200:467-475.

Cohen D, 1966. Optimizing reproduction in a randomly varying environment. J. Theor. Biol. 12:119-129.

Davison J, 1969. Activation of the ephippial egg of Daphnia pulex. J. Gen. Physiol. 53:562-575.

Delbare D, Dhert P, 1996. Cladocerans, nematodes and trochophora larvae, p. 283-295. In: P. Lavens and P. Sorgeloos (eds.), Manual on the production and use of live food for aquaculture. FAO Fisheries Technical Paper 361. FAO, Rome.

De Meester L, 1993. Inbreeding and outbreeding depression in Daphnia. Oecologia 96:80-84.

De Stasio BT, 1989. The seed bank of a freshwater crustacean: copepodology for the plant ecologist. Ecology 70:1377-1389.

Evans MEK, Dennehy JJ, 2005. Germ banking: bet-hedging and variable release from egg and seed dormancy. Q. Rev. Biol. 80:431-451.

Frisch D, Morton PK, Chowdhury PR, Culver BW, Colbourne JK, Weider LJ, Jeyasingh PD, 2014. A millennial-scale chronicle of evolutionary responses to cultural eutrophication in Daphnia. Ecol. Lett. 17:360-368.

Gąsiorowski M, Hercman H, 2005. Recent sedimentation and eutrophication of Kruklin lake after artificial drop in waterlevel in the middle of 19th century. Studia Quaternaria 22:17-25.

Gleason RA, Euliss NH, Hubbard DE, Duffy WG, 2003. Effects of sediment load on emergence of aquatic invertebrates and plants from wetland soil egg and seed banks. Wetlands 23:26-34.

Grabowski T, 2006. [Utilisation of seston traps for dormant period assessment of planktonic cladocerans of the genus Daphnia].[Bachelor's thesis in Polish]. University of Warsaw.

Gyllström M, Hansson L-A, 2004. Dormancy in freshwater zooplankton: Induction, termination and the importance of benthic-pelagic coupling. Aquat. Sci. 66:274-295.

Hairston NG, Kearns CM, 2002. Temporal dispersal: Ecological and evolutionary aspects of zooplankton egg banks and the role of sediment mixing. Integr. Comp. Biol. 42:481-491.

Hann BJ, 1995. Invertebrate associations with submerged aquatic plants in a prairie wetland. UFS (Delta Marsh) Annual Report 30:78-84.

Herzig A, 1985. Resting eggs - a significant stage in the life cycle of crustaceans Leptodora kindtii and Bythotrephes longimanus. Verh. Internat. Verein. Limnol. 22:3088-3098.

Holmer M, Storkholm P, 2001. Sulphate reduction and sulphur cycling in lake sediments: a review. Freshwater Biol. 46: 431-451.

Jańczak J, 1999. [Atlas jezior Polski - Tom III].[Book in Polish]. Bogucki Wydawnictwo Naukowe S.C., Poznań: 240 pp.

Kasahara S, Onbé T, Kamigaki M, 1975. Calanoid copepod eggs in sea-bottom muds. III. Effects of temperature, salinity and other factors on the hatching of resting eggs of Tortanus forcipatus. Mar. Biol. 31:31-35.

Kearns CM, Hairston NG, Kesler DH, 1996. Particle transport by benthic invertebrates: its role in egg bank dynamics. Hydrobiologia 332:63-70.

Kerfoot WC, Budd JW, Eadie BJ, Vanderploeg HA, Agy M, 2004. Winter storms: Sequential sediment traps record Daphnia ephippial production, resuspension, and sediment interactions. Limnol. Oceanogr. 49:1365-1381.

Kotarba A, Łokas E, Wachniew P, 2002. ${ }^{210} \mathrm{~Pb}$ dating of young Holocene sediments in high-mountains lakes of the Tatra Mountains. Geochronometria 21:73-78.

Krupińska K, 2014. [The search of environmental signals breaking diapause in organisms inhabiting temporary and permanent waters].[Bachelor's thesis in Polish]. University of Warsaw.

Lutz RV, Marcus NH, Chanton JP, 1992. Effects of low oxygen concentrations on the hatching and viability of eggs of marine calanoid copepods. Mar. Biol. 114:241-247.

Maerki M, Müller B, Dinkel C, Wehrli B, 2009. Mineralization pathways in lake sediments with different oxygen and organic carbon supply. Limnol. Oceanogr. 54:248-438.

Marcus NH, 1984. Recruitment of copepod nauplii into the plankton: importance of diapause eggs and benthic processes. Mar. Ecol. Prog. Ser. 15:47-54.

Marcus NH, 1996. Ecological and evolutionary significance of resting eggs in marine copepods: past, present, and future studies. Hydrobiologia 320:141-152.

Meier JA, Jewell JS, Brennen CE, Imberger J, 2011. Bubbles emerging from a submerged granular bed. J. Fluid Mech. 666:189-203.

Müller B, Buis K, Stierli R, Wehrli B, 1998. High spatial resolution measurements in lake sediments with PVC based liquid membrane ion-selective electrodes. Limnol. Oceanogr. 43:1728-1733.

Onbé T, 1978. Sugar flotation method for sorting the resting eggs of marine cladocerans and copepods from sea-bottom sediment. Bull. Japan. Soc. Sci. Fish 44:1411.

Paes TASV, Rietzler AC, Pujoni DGF, Maia-Barbosa PM, 2016. 
High temperatures and absence of light affect the hatching of resting eggs of Daphnia in the tropics. An. Acad. Bras. Ciênc. 88:179-186.

Pancella JR, Stross RG, 1963. Light induced hatching of Daphnia resting eggs. Chesap. Sci. 4:135-140.

Pérez-Martínez C, Jiménez L, Moreno E, Conde-Porcuna JM, 2013. Emergence pattern and hatching cues of Daphnia pulicaria (Crustacea, Cladocera) in an alpine lake. Hydrobiologia 707:47-57.

Pietrzak B, Ślusarczyk M, 2006. The fate of ephippia - Daphnia dispersal in time and space. Pol. J. Ecol. 54:709-714.

Radzikowski J, 2013. Resistance of dormant stages of planktonic invertebrates to adverse environmental conditions. J. Plankton Res. 35:707-723.

Revsbech NP, Jørgensen BB, Blackburn TH, 1980. Oxygen in the sea bottom measured with a microelectrode. Science 207:1355-1356.

Ritvo G, Kochba M, Avnimelech Y, 2004. The effects of common carp bioturbation on fishpond bottom soil. Aquaculture 242:345-356.

Rother A, Pitsch M, Hulsmann S, 2010. The importance of hatching from resting eggs for population dynamics and genetic composition of Daphnia in a deep reservoir. Freshwater Biol. 55:2319-2331.

Schultz TW, 1977. Fine structure of the ephippium of Daphnia pulex (Crustacea: Cladocera). Trans. Am. Microsc. Soc. 96:313-321.

Schwartz SS, Hebert PDN, 1987. Methods for the activation of the resting eggs of Daphnia. Freshwater Biol. 17: 373-379.
Stross RG, 1966. Light and temperature requirements for diapause development and release in Daphnia. Ecology 47:368-374.

Surga K, 2007. [Production of resting eggs of Daphnia cucullata in the lakes of north-east Poland].[Master's thesis in Polish]., University of Warsaw.

Sweerts J-PRA, De Beer D, 1989. Microelectrode measurements of nitrate gradients in the littoral and profundal sediments of a meso-eutrophic lake (Lake Vechten, The Netherlands). Appl. Environ. Microbiol. 55:754-757.

Ślusarczyk M, 1999. [Diapauza skorupiaków planktonowych jako mechanizm obrony przed drapieżnictwem].[Article in Polish]. Kosmos 48:465-476.

Pinceel T, Vanschoenwinkel B, Uten J, Brendonck L, 2013. Mechanistic and evolutionary aspects of light-induced dormancy termination in a temporary pond crustacean. Freshwater Sci. 38:517-524.

Uye S, 1980. Development of neritic copepods Acartia clausi and A. steueri. Bull. Plankton Soc. Japan 27:1-9.

Uye S, Fleminger A, 1976. Effects of various environmental factors on egg development of several species of Acartia in Southern California. Mar. Biol. 38:253-262.

Uye S, Kasahara S, Onbé T, 1979. Calanoid copepod eggs in sea-bottom muds. IV. Effects of some environmental factors on the hatching of resting eggs. Mar. Biol. 51:151-156.

Vandekerkhove J, Declerck S, Brendonck L, Conde-Porcuna JM, Jeppesen E, De Meester L, 2005. Hatching of cladoceran resting eggs: temperature and photoperiod. Freshwater Biol. 50:96-104.

Wolf HG, Carvalho GR, 1989. Resting eggs of lake-Daphnia. II. In situ observations on the hatching of eggs and their contribution to population and community structure. Freshwater Biol. 22:471-478. 